\title{
Mindful by routine: Evidence from the Italian Air Force Tornado crews flying practices
}

\section{LaURa Frigotto and Marco Zamarian}

\begin{abstract}
Organization studies have long focused on the problem of understanding the possibility of pursuing effectiveness and resilience at the same time. An emerging perspective, reconciling mindfulness and routines, allows to address these contrasting goals: routines channel the exploratory nature of mindfulness, but they also support it by providing context to its enactment. Despite these results, available empirical evidence from mindful organizations has not helped understand how mindfulness can be supported by routines without losing its broader scope of attention. Moreover, an operational definition of mindfulness is still an open question.

In this paper, we adopt an analytical framework allowing to break down routines into their sensing and reacting components. Using evidence from the flying practices of Tornado crews in the Italian Air Force, we show that mindfulness concerns the parallel activation and re-combination of these components, allowing the rapid deployment of responses but also the continuous reassessment of the situation.
\end{abstract}

Keywords: experiential knowledge, organizational structure, control and coordination mechanisms, knowledge acquisition and sharing

Received 6 November 2013. Accepted 3 September 2014

\section{INTRODUCTION}

$\mathrm{O}$ rganization studies have long focused on the problem of understanding the possibility of pursuing efficiency and resilience simultaneously (see Kantur \& Iseri-Say, 2012 for a review on resilience). Among several contributions on the issue, an emergent perspective (Sutcliffe \& Vogus, 2014) relating organizational mindfulness (Weick, Sutcliffe, \& Obstfeld, 1999) and routines (Nelson \& Winter, 1982, Winter, 2004) has recently been proposed in the literature (Levinthal \& Rerup, 2006; Weick \& Sutcliffe, 2006; Rerup \& Levinthal, 2014). In particular, such perspective allows organizations to address the contrasting goals (March, 1991; Rerup \& Levinthal, 2014) that are experienced when pursuing mindful behaviours through routines. The explorative nature of mindfulness is challenged by routines. As organizations try to stabilize responses and standardize behaviours, they also narrow down the scope of attention and the other resources (time, effort) devoted to single instances. Conversely, mindfulness is supported by routines that define the way mindfulness should be enacted.

The way in which such contrasting forces are reconciled is crucial to the deployment of mindfulness and to the understanding of the essence of mindfulness. However, available empirical evidence from

Department of Economics and Management, University of Trento, Trento, Italy

Corresponding author: marialaura.frigotto@unitn.it 
mindful organizations has not helped in understanding how mindfulness can be built and supported by routines without losing a broader scope of attention (Rerup \& Levinthal, 2014). Moreover, an operational definition of mindfulness clarifying components and peculiarities is still a challenge to the existing literature (Lekka, 2011).

In this paper, we adopt Sidney Winter's (2004) conceptualization of organizations into evolutionary systems of sensors and reactors via an analytical framework that allows us to map cognition and action in routines. We have conducted a case study with the purpose of inductively studying mindfulness and its relation to routines. We will generate a definition of mindfulness as the parallel activation (combination) of sensors and reactors with diverse purposes and refinements, which can also serve as operationalized definition of mindfulness.

We chose a case where we could find both mindfulness and the need for highly reliable and homogeneous behaviours across organizational members, often taking the form of routines. Given that mindfulness was identified as a property of high reliability organizations (Roberts, 1990; LaPorte \& Consolini, 1991; La Porte, 1996; Weick \& Sutcliffe, 2001), that is organizations that face extremely threatening and uncertain environments (Perrow, 1999) and nevertheless they display safety, robustness and reliability, we selected as our field of research Tornado crews of the Italian National Air Force that provided such records. The Italian Tornado crews also met another requirement we used to select our empirical field: they displayed a highly standardized context where flight and missions expertise is formalized and amply shared within all UN Tornado crews through standard operating procedures and contingency rules.

Our contribution is the following. First, we contribute to the literature on mindfulness and routines by clarifying the role of routines in building mindfulness. Second, we provide an inductively generated and analytical definition of mindfulness, as the lack thereof provided a constitutive/constitutional critique in regards to theories on mindfulness. Third, we contribute to the literature on routines by introducing an analytical framework to map how routines are recombined.

The rest of the paper is structured as follows. The next paragraph presents the literature at the crossroads of mindfulness and routines we build on. In the third paragraph we introduce our analytical framework, building on Winter's (2004) distinction between sensors and reactors as elements of organization systems. Then we offer a description of the research method and the empirical setting we employed to investigate the relationship between the sensing and the acting dimensions in complex organizations. Paragraph five and six illustrate the main empirical evidence we collected in the form of a case study. Then, we move to an analysis of the case, and to our main theoretical contributions, followed by the conclusions.

\section{MINDFULNESS AND ROUTINES}

Organizational mindfulness is 'the quality of collective attention that enables managers and employees to minimize errors, remain vigilant, and respond effectively to unexpected events' (Rerup \& Levinthal, 2014: 33-34). It includes the quality of attention, the consequence of attention, that is 'what people do with what they notice' (Weick, Sutcliffe, \& Obstfeld, 1999: 90) and the conservation of attention. Mindfulness supports organizations to be continuously alert to and more receptive of early signals of trouble (Rerup, 2005), to track small failures, to resist oversimplification, to remain sensitive to the operations in practice, and to define responsibility of decisions on expertise rather than authority (Weick, Sutcliffe, \& Obstfeld, 1999). It is opposed to mindlessness where early and simple assessments lead to a plan of responses that often consists of available routines, and that is implemented until the plan runs its course or failure is evident (Weick \& Sutcliffe, 2001).

Consistently, routines have traditionally been conceived as mindless (e.g., Ashforth \& Fried, 1988; Langer, 1989). In fact, people follow routines without devoting cognitive attention to them, and they 
economize cognitive resources by executing actions in the realm of the unconscious (Becker, 2004). However, empirical work suggests that routines are built of cognition (Pentland \& Rueter, 1994), as people do not just recall and reproduce them but have the choice to amend them and to decide how to do so.

Recent contributions have shown that organizational mindfulness can be embodied in routines (Levinthal \& Rerup, 2006). In fact, routines foster organizational mindfulness in several ways. First, by setting expectations that stimulate people to raise their attention to threatening cues of variation (Weick \& Roberts, 1993; Rerup, 2009). Second, by deploying mindful principles at the micro-level of everyday practices (Rerup, 2009). Third, by building the repertoire of behaviours the organization or the individual can draw upon and recombine to respond to unexpected situations (Bigley \& Roberts, 2001; Weick \& Sutcliffe, 2001).

However, the role of routines in mindfulness is also problematic for at least two reasons. First, routines typically restrict the focus of attention to experienced conditions rather than to signals of change. In fact, routines primarily store efficient solutions to frequent situations, and such solutions often become institutionalized, even become norms, as they become standard operating procedures. Mindfulness instead supports the attitude to discuss each variation from the standard case as that would reveal a different nature of the case itself and imply a challenge. However, when this attitude of mindfulness becomes routine, its receptiveness and openness to variations typically decreases as the selective eye and the ability to deploy solutions strengthens. Second, routines are of higher value in stable conditions: they have shown to be reliable in the past and they imply a low cost of implementation and search. Conversely, mindfulness implies higher implementation costs coeteris paribus. However, contexts and situations where there is no similarity of the future to the past, and where there is a high cost associated with failure, are the main motivation for mindfulness.

Mindfulness conceptually is the quality of attention that shuns the traps provided by the narrow focus, the efficiency and the past reliability that routines provide. How this is made possible through routines themselves still presents a challenge, both for speculation and for inductive theories of mindfulness.

\section{ANALYTICAL FRAMEWORK}

Mindfulness recalls the original attention to cues in the environment that is typical of the stages in which routines have not yet formed and the screening of the environment has not yet become selective for signs of known contexts. With such an open scope of attention, options are infinite and choice is indefinite. At the opposite, when routines have settled down, attention is selective, options are listed and choice is typically retrieved among them. At the conceptual level, combined mindfulness and routine situations build the ends of an evolutionary path wherein costs are reduced and efficiency is increased, and where organizations typically move along evolution from open, mindful behaviours to focused, routinized ones.

Winter (2004) describes this journey as the change in evolution from general sensor-reactor systems to specialized sensor-reactor systems that concerns organizations as well as biological organisms. In this view, organizations are a set of 'sensors', tasked with monitoring the environment, and 'reactors', devoted to producing a response to the stimuli thus perceived. Within inexperienced organizations, sensor-reactor systems are general, addressing a broad range of stimuli and providing broad, sometimes ineffective responses. Evolution, through experience, then, produces specialization and efficiency, when relevant environmental signals are repetitive and associated solutions become clear, stable and secure. Over time, specific sensor-reactor systems for frequent and relevant situations are identified and they are substituted to general systems. This happens according to (i) the frequency and the variety of stimuli that organizations are exposed to, and (ii) the impact (in terms of win/loss) of facing such 
(a)

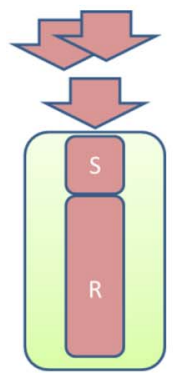

(b)

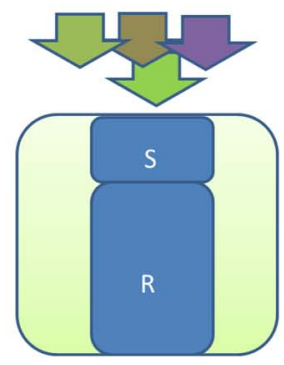

(c)

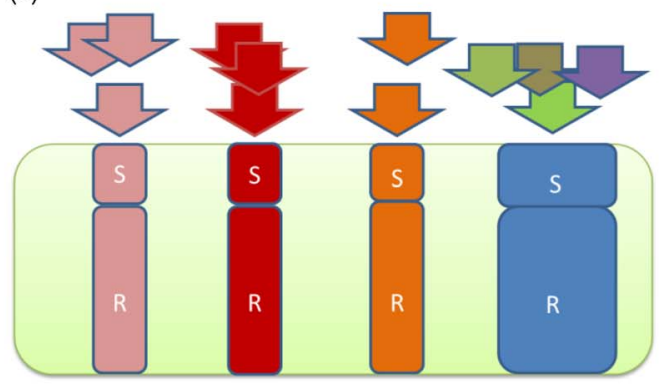

Figure 1. Alternative representations of the sensor-reactor systems. Situation (a) depicts a specialized sensorREACTOR SYSTEM. SITUATION (b) REPRESENTS THE TYPICAL SOLUTION TO SITUATIONS WHERE HETEROGENEOUS OR AMBIGUOUS STIMULI PREVAIL AND A GENERIC SENSOR-REACTOR IS ADOPTED. SITUATION (c) DESCRIBES A MIXED SOLUTION WHERE GENERIC SENSOR-REACTOR SYSTEMS (IN BLUE) COEXIST WITH STIMULUS-SPECIALIZED SYSTEMS (IN PINK, RED AND ORANGE)

situations, through a cost-benefit analysis based on the assessment of risk (combining frequency and impact). However, the tendency is to build specialized sensor-reactor systems and to keep general sensors only for residual situations where the specific reactions and solutions cannot apply. At the extreme of efficiency, general sensors are completely abandoned, thus rendering organizations unable to respond effectively when new or infrequent cases arise.

Winter offers an interesting metaphorical example in regards to this point. Some species of moths have developed a very sophisticated detector, which is similar to a sonar, for perceiving the shaking of bats' wings, bats being their major predators, and such moths can consequently employ an evasive dive maneuver to escape from them: this is an example of highly specialized sensor-reactor systems (Figure 1a). Specialized systems are more efficient and are extremely effective in reaction to the kind of stimuli for which they were designed. Yet, they are extremely vulnerable to any other condition: moths cannot hear anything aside from bats and are likely to die from a rolled paper in our houses.

From the same natural context, Heiner's (1983) representation of prey behaviour may be a good metaphor for general sensor-reactor systems (Figure 1b). In response to any signal coming from the environment which is not immediately recognized as a mate or food (sounds, sights, smells), preys activate the same reaction: they flee. Generic systems are less precise, and thus are costly, as their reaction is unnecessary in many cases, for example when unusual noises are not coming from threats. Nevertheless, they have a higher chance to respond to uncertainty and they always provide some kind of answer. As such, they display resilience.

In complex adaptive systems (Cohen \& Levinthal, 1990; March, 1991; Levinthal \& March, 1993; Denrell \& March, 2001; Winter, 2004; March, 2006), given internal and external complexity, the two systems typically coexist in organizations (Figure 1c). However their coexistence is typically ruled by some kind of division of labor. Different systems address different sets of stimuli. Specialized sensors capture known situations and activate specialized responses, while for new challenges or unusual ones, general systems are in place. Their activation follows a sequence: if specialized systems fail, general sensors are mobilized. Moreover, sensor-reactor systems are conceived as sets of cognition and action, displaying the same level of specialization or generality ${ }^{1}$.

We adopt the distinction between specialized and general sensors and reactors as our analytical framework in this paper. This allows us to map the cognitive and the operational components of

1 We will refer to the association of sensor and reactor at the same level of specialization with the expression 'vertical combination' of the sensor-reactor system. 
routines at two different scope levels, providing the ability to observe recombination of routine chunks according to their role, and to understand the essence and the analytical components of mindfulness.

\section{RESEARCH STRATEGY}

In this paper, we inductively study mindfulness and its relation to routines through a single-case empirical analysis (Yin, 1994) of a mindful organization. Through this empirical observation, we aim to generate a theory on the role of routines in mindfulness and on the constituents of mindfulness itself (Glaser \& Strauss, 1967; Glaser, 1992; Siggelkow, 2007). This method is suitable to gain a consistent understanding of the mindfulness phenomenon and to contribute to the advancement of its theoretical framework (Vaughan, 2004; Suddaby, 2006; Le Coze, 2008).

The analysis adopts a grounded theory approach (Glaser \& Strauss, 1967; Glaser, 1978), where a phase of open coding is combined with a second phase in which open codes are matched against the theory-driven concepts derived from our analytical framework. A third phase of theorization follows where we address the relationship between concepts.

The empirical setting selected for the purpose of the study is the Italian Air Force in which we focused on a particular wing $\left(6^{\circ}\right.$ Stormo), which flies Panavia Tornado fighter-bombers. We chose Tornados because such airplanes require a crew of two people whose roles - pilot and navigator - are structured around a strict division of interactive labour. As such, they can be considered the simplest possible team in which we still have coordination dynamics as well as more complex interactions with external actors and organizations, such as the control tower.

Tornados are devoted to reconnaissance and combat missions, the latter being missions consisting in bombing targets while defending from possible hostile interceptors or ground-based weapons systems. Despite extremely threatening and uncertain environments, Tornado crews display safety, robustness and reliability. For these reasons (Roberts, 1990; LaPorte \& Consolini, 1991; La Porte, 1996; Weick \& Sutcliffe, 2001), we include the Tornado wing among high reliability organizations, and we consider the Tornado crew as a micro high reliability organization. Moreover, while missions can be carried out solo or in complex formations, we focused on solo training missions as these make up a vast majority of the training and practice missions and thus are also more clearly and frequently observable.

The case study is based both on primary and secondary source data, collected at the various levels of the organizational structure, that include archival records, interviews, and direct observations of simulated and effective flights procedures as well as other activities (Table 1 details our data collection). The systematic triangulation of such data sources (archival documents, interviews and observations) provides internal validation and reliability to the analysis and the findings (Yin, 1994: 98-99). We present the result of our analysis as a narrative including first-hand accounts by the crew members we interviewed that we found particularly useful in giving insight to the reader.

\section{AN OVERVIEW OF THE TORNADO: SENSORS AND REACTORS AND THE CREW}

Operating an attack two-seater as a Tornado is a complex and dangerous activity. In this Section, we will provide an overview of the Tornado as a micro-organization.

The main feature of this plane is its two-man crew with a distinctive division of labour between the pilot, in charge of flying the plane and deploying the weapons, and the navigator, who manages the radar, sets the route, and operates other electronic devices on the plane. This division of labour has several consequences in regards to how the crew operates. We will characterize this, first, in terms of how information is gathered and understood and, second, of how coordinated action is achieved. Following our analytical framework, we interpret all the actions aimed at gathering and making sense 
TABLE 1. INFORMATION ON FIELDWORK ACTIVITY

Archival documents

Material for external communication or available to a restricted public

General information on the Italian National Airforce: www.aeronautica.difesa.it

Official presentations of the wing

DVD commemorating the wing's 50th anniversary

Review 'Security of the Flight', years 2005, 2006, 2009

Internal-only documents

Formal repertoires of contingency plans for quick reference (avionic - weapon check list)

Theory and operations manuals of flight and weapons

Archive of failures

Flight plans

Risk matrices

Interviews

Commanding General (attack and reconnaissance forces)

Wing commander

Flight security Chief Officer

Chief Operative Officer

Pilots

Navigators

Trainer-pilots

Support personnel

Total

Field observations

Simulated flight activities

Observation of flight and weapon simulation by expert crew and emergency handling procedure

Observation of simulated debriefing by experts

Observation of flight simulation by rookies

Observation of simulated debriefing by rookies

Flight simulation by the two researchers

Real flight activities

Observation of take off and landing procedures

Observation of flight preparation procedures, dress up, pre-flight meetings, pilot/navigator pre-flight 1 each briefing, cartographic briefing, post-mission debriefing

Other observations

Observations of interactions among personnel (days)

Observations of barracks life and procedures on base during day/night (days)

Observations of base spaces and logistics operations (days)

of the information as sensors of the crew. On the same base, we interpret all the actions concerning the conduction of operations, as reactors.

First, the information needed to fly successfully essentially depends on five sources: the direct observation of the environment through the canopy, the inputs from the plane information system in the shape of visual aids, inputs from the other crew member and communications occurring with external sources (mainly ground control and other planes of the formation), and inputs from printed materials (emergency checklists, maps, manuals). The ability to observe the environment is highly skewed: the pilot, sitting to the front, has a good visibility out of the canopy. The navigator, to the back, by contrast, has a partial and lateral view outside. The two cockpits are obviously different and require the exclusive attention of their operator, as they need to accommodate two separate sets of devices and controls, with the exception of a common set of LED alarms that signal the occurrence of problems in the aircraft. Each combination of lights in the panel corresponds univocally to a specific case (status or failure) of the plane. 
Moreover, the two members of the flight unit are physically separated and need to communicate by an internal radio system embedded in their helmets. Thus, the information flux is only partially shared between the crew members; however, it is often necessary to consider the two information bases together in order to build a complete understanding of the situation at hand. The flight benefits from a specialized monitoring of particular information sources, which avoids information overload and introduces interdependence in the phase of information gathering, thus stimulating reciprocal attention. This design also has the purpose of introducing a form of continuous control, as activities are always interactive, as well as a form of support in response to serious alarms or ambiguous signals. The information flux derived from both crew members is extremely relevant and particularly critical as it reflects individual communication styles and team building issues that are only slowly learned through experience.

You learn little by little, everyone has a personal technique of communication. I will not hide the fact that sometimes that's the [main] drawback of two-seater aircrafts. This is why the training in Crew Resource Management we receive is meant to, ... well ok, we are taught CRM mainly to take care of dangerous situations, so it is, in fact, the basic component of our performance, no matter how we define it. So, a performance will be positive if the crew producing it functions as a team and training to exchange information [properly] is one of the main tasks of the crew members who are operationally involved with flights every day [...] (Pilot Major 1)

We interpret instruments and alarm panel as the specific sensors of the crew, and look-out, communications between crew members and radio communications as general sensors.

Concerning the domain of action, action is highly standardized and routinized into rules that display diverse degrees of specialization. At the most general level there are the so-called 'basic rules' pilots and navigators are encouraged to follow at all times. These are generic heuristics that provide a framework to act in a way that allows the aircraft immediate survivability and buys the crew time to produce effective strategies to react to the environment. At a higher level of specialization, there are avionic and emergency checklists that are specific step-by-step procedures, formalized into checklist booklets. The emergency checklist booklet codifies a series of actions to undertake in order to react to single or combined alarms or anomalous flight instruments values.

We interpret avionic and emergency checklists as the specific reactors, while basic rules are categorized as general reactors.

Moreover, in the realm of action, the same interdependence and the same benefits and difficulties exist as for the realm of information. In principle, the actions of the pilot in conducting the plane and the actions of the navigator in route tracing may be thought of as independent of each other. However, in many cases, tasks are divided in a close sequence between pilot and navigator in such a way that the completion of one activity is the necessary condition for its execution by the other crew member. Checklist booklets are the same for pilots and navigators and both pilot and navigator have it in a special pocket of their suits, however the checklist is consulted by the navigator in the majority of circumstances.

I do bring my checklist, but I keep it close at all times. It is not expected of me [by the procedures to open it] when we talk about alarm checks. (Pilot Captain 1)

In order to activate a successful response, there are two critical steps: the recognition of the codified category to be recalled and the response implementation. On Tornados, the system of instruments and alarms selects and interprets signals for the crew, who can concentrate mainly on the response.

\section{THE FLYING PRACTICES OF TORNADO CREWS}

We describe in this Section the repertoires of flying practices that allow the survivability of the aircraft during missions. 


\section{Vertical sensor-reactor combinations: the consistent use of procedures to overcome troubles}

In order to successfully fly their mission, crews deploy a procedural approach. In this line of action, a successful flight relies on the correct execution of a set of responses to the perceived, relevant, states of the world. This strategy entails two steps; First, there is a need for a correct interpretation of the information coming from the several channels available to the crew. Then, effort is exerted in remembering the correct set of actions to activate given the situation, as reconstructed from this information. In order to aid this process, crews are supported by Standard Operating Procedures detailing activation conditions and a step by step description of the actions to undertake to correctly respond to the situation at hand. Crew members are required to memorize and internalize the so called bold faces of each procedure before they are allowed to fly missions. Bold faces consist of limited lists of actions designed to stabilize the situation, thus giving sufficient time to the navigator to consult the physical copy of the Avionics or Emergency checklists they carry on their suits. During the bold face phase of the procedure the navigator informs the pilot of the next action to perform, while he/she recovers the complete checklist. The pilot, in turn, confirms each action and executes it. After this first phase, the crew goes through the rest of the procedure using the same method, but this time the navigator reads the steps from the physical checklist. The correct completion of the procedure translates almost invariably into an effective solution. A good example of the use of this technique that we observed is the link between given configurations of lights on the alarm panel and the activation of a corresponding procedure. Each configuration of alarm LEDs uniquely identifies an emergency and corresponds to a specific recovery procedure detailed in the emergency checklist.

Given the complexity of the aircraft and the amount of possible failures in its systems, obtaining an adequate knowledge of the procedures requires a considerable amount of time and cognitive resources. However, the results reached via this method are very consistent across the crews of the wing. From direct observation of the performance of expert and novice crews, and anecdotal evidence presented in the interviews, differences in performance are negligible when procedure-based behaviour is implemented.

\section{Diagonal sensor reactor combinations: 'out of context' connections}

We observed the performances of two crews with different amounts of experience facing the same simulated incident in the flight simulator.

Crew number 1 was composed of two novice elements undergoing operational readiness training. Crew number 2 had two expert members with around 2000 flight hours of experience and had taken part in combat missions. The two crews were subject to the same incident: a serious system failure requiring an emergency landing, and a subsequent engine failure requiring one of the two engines to be switched off during descent. This second failure is extremely dangerous as the (reverse) thrust from both engines is normally required to help the plane reduce its speed both before and right after landing. We were told by the officer in charge of the exercise that this specific combination of failures is an extremely rare occurrence with no ready-made procedure available to the crews.

Crew number 1 reacted to the first system failure as expected: they communicated to ground control the need to land immediately and started the landing procedure following the authorised landing path. When the second failure occurred, after a few moments of disconcert, they identified it correctly in the alarm control panel, started the regular procedure associated with the failure in the appropriate checklist in the manual, switching off the engine. During the descent they realized that the speed was too high and started a very brief brainstorming session to come up with a solution, with the navigator talking to the pilot frequently. Approaching the runway, they finally decided to use the tailhook to cut down the speed after landing. However, the approach was not straightforward, as the thrust came from just one engine, and the crew failed to compensate for that. The hook missed the arresting wires, 
bouncing on the tarmac. Fortunately, the plane was able to come to a stop just leaning with its nose on top of the barbed-wired fence surrounding the base, with minimal damage to its wheels and suspensions, and light damage to the canopy and systems lodged in the nose of the aircraft.

Crew number 2 reacted to the first failure as expected, communicating appropriately and starting descent. At the occurrence of the second failure, the crew seamlessly reacted by switching off the damaged engine, communicating again with ground control asking them to ready emergency teams on the runway in case of incident, and readying themselves for landing. Recalling an emergency procedure normally used on carrier landings, the pilot tilted the plane at the time of the release of the hook, connecting to the wire and stopping the plane at the middle of the runway with no damage.

The difference in behaviour between the two crews is apparent. The inexperienced crew attempted to find a solution for the 'strange' emergency by going back to checklists and applying them to the situation at hand, as best as they could. In other words, they connected their representation of the situation to an action that corresponded to this representation, to the best of their knowledge. Using a specific sensor (the alarm set off by the engine failure) they went searching for its specific solution. However, the emergency procedure had not been designed for the specific combination of problems defining the situation at hand, and this resulted in a costly mistake. This mistake was compounded by the fact that the two-crew members communicated frequently between themselves but forgot to transmit critical information to ground control. Moreover, the continuous chatter by the navigator irritated the pilot and may have distracted her. The second crew reacted differently and creatively. They immediately sensed the complexity of the problem and went searching for a solution recalling a context (landing on aircrafts). The solution called for a modification of the landing approach to account for the current combination of problems, and consequently applied an unconventional solution. The words of one of the expert pilots of the wing help to better understand the difference:

[...] the achievement of a positive performance, [that for us] translates into surviving and taking home the target. In the end, it is a very simple proposition, nothing more. If the crew acted effectively to survive to the contingent threats, but most of all to hit the assigned target [we achieve a good performance]. So, if we start from this premise, the interpretive key is very simple, if the navigator tells the pilot something while the pilot ['s attention] was already saturated doing something else, you have already identified the problem. (Pilot Major 1)

This kind of solution to problems does not pertain solely to obviously low-risk situations, such as simulated exercises of the kind just described, it is a strategy available to crew members having experienced a wide variety of contexts, either directly or by sharing stories with their peers. An anecdote, reported by several officers, talked about a specific situation with the alarm panel. A specific configuration of LED lights signals (or rather, should signal) the failure of an engine. The reaction by the book would consist in a procedure to switch off the damaged engine and continue the flight with the surviving engine. However, experienced crews know of an alternative explanation to the pattern of lights they see on the panel: there have been cases where one of the engines overheats to the point of melting its internal sensors (that thus are not able to signal the failure on the panel) and of activating the sensors of the other engine. Following the book would mean switching off the only functioning engine and sending more fuel to the overheated one, thus provoking its explosion. The out-of-the-box solution consisted in testing the alarm panel for anomalies. They manually switched the LED lights connected to each engine in order to check if they did not turn on because the light was broken. If these tests result in a confirmation of engine failure and not malfunctioning lights, then the book solution is viable, otherwise the aircraft has a dramatically overheating engine. In this latter, and fortunately rarer case, the crew needs to switch-off the only apparently working engine and rely on the other one.

In both cases we described, there is an obvious mismatch between the signal coming from the sensing system and the activated reaction. Experienced crews are able to decouple the vertical 
combination of sensors and reactors typical of procedural decision making, and recombine sensors and reactors in cases where contextual conditions hint at the possibility of transferring a procedural response from one domain to another one. Naturally, the ability rests in possessing a profound knowledge of alternative contextual conditions.

\section{The horizontal activation of sensors: the concept of situational awareness}

As one of the pilots we quoted said, the first aim of any mission is 'to bring the target home', an expression which underlies a variety of aims that a flight might have. Nevertheless, the completion of any mission depends on the ability of the crew to keep control of the aircraft as further activities (reconnaissance or attack) are inevitably added into this primary one.

'To fly' a Tornado, as we have detailed in the previous sections, is a complex activity which requires the consideration of a large set of information related to the condition of the aircraft, the course, the proximity to the target, meteorological conditions and air traffic conditions, the flight instruments and warning lights, and communications between crew members and radio transmissions (see Figure 2). The capability of handling these informational sources is functionally connected to the so-called 'SA' that is situational awareness, which represents the ability to correctly allocate attention and prioritize incoming information. In sum, it represents a synthetic sensor combining the discrete sensing devices available to the crew.

All our interviewees found it very difficult to describe what SA is, and specific documental material is exhaustive in displaying the tacit nature of this competence. SA is referred to as 'an ability to combine environmental signals and intuitions into an ordered mental 3D picture film' of the present, past and future states (Safety of the flight, 251/2005)'. For this purpose, the visualization of the situation allows the crew to acquire awareness of potential threats, to simulate a reaction and to anticipate consequences and reaction. This is an imaginative activity which does not neglect any dimension of experience as it aims at 'building a picture' of the situation, with accompanying sounds and sensations, but before the event actually takes place, before the aircraft arrives to it and before its instruments may be able to map it. Crews call this activity 'to stay ahead of the aircraft'.

A high level of SA occurs when the crew is able to use and connect information coming from one of the possible channels into information flows pertaining to alternative sources. They connect sensors to other sensors to add meaning to the information gathered by each source. An example of this ability regards the use of alternative sources to validate information coming from a focal source: in one episode a navigator reported a signal he interpreted as a small flock of large birds ${ }^{2}$. The first set of reactions the crew implemented consisted in focusing the attention on visuals (actual observation out of the canopy) and different radar readings (ground control). Only when they had a clear picture of the situation by triangulating information coming from the alternative sources, did they start thinking of a course of action.

SA is a basic competence which should be present while performing other activities. The main source of SA is experience, and there are no precise indications on how to acquire it. In fact, when SA decreases, in order to restore it, crews refer to general and simple principles that are heuristics designed to increase available time for problem solving, rather than to define a procedure for solving problems in complex situations (see Table 2). This problem solving ability is in fact considered an endowment. The implicit idea is that if SA is maintained at a certain level, gathering and interpreting information becomes simple. There should not be ambiguous or unexpected situations which require a complex problem solving. Complexity and thus, high cognitive cost emerges only when SA is low. As a

2 This is actually one of the most feared situations by crews as even one large bird can seriously damage or even destroy an engine as ceramics are mostly used in engines, to endure very high temperatures. 


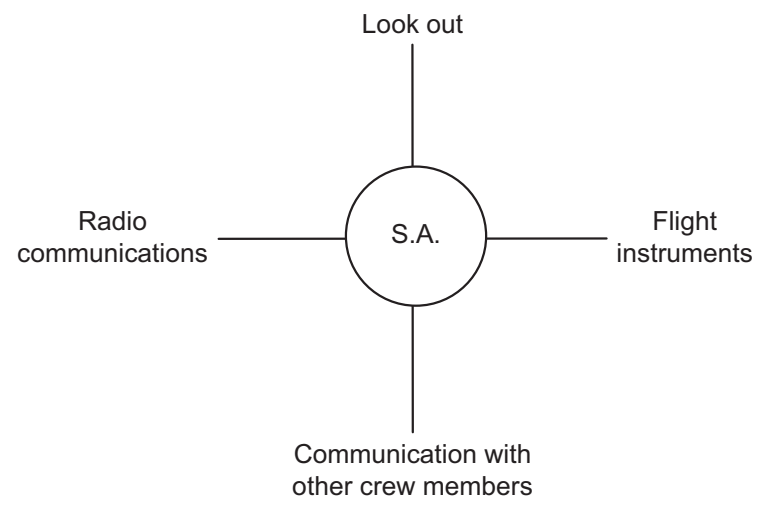

Figure 2. The components of Situational aWARENEsS

TABLE 2. BAsic RULES For maintaining SitUational aWARENESS

1. Respect standards

2. Communicate deviations from the expected/planned and intentions on what to do

3. Avoid mental saturation

4. Do not take anything for granted

5. Act openly with no concern for roles or positions

matter of fact, when SA is adequate, 'perceptions correspond to what is actually taking place' and response is simply selected from a rich repertoire of consolidated solutions linked to a set of expected problems.

Such a design of the perceptual system has the advantage of reassuring crews as all issues and corresponding solutions that may be required are readily available This sense of security is acknowledged to be an essential requirement for engaging in combat missions. It provides the crew with no complex set of procedures, which would always be inadequate to unforeseen and unknown situations. Instead, it endows them with simple and general level principles which leave them the responsibility to find solutions but provide the contextual conditions for this to happen (increases in available time as well as reassurance, which minimizes panicking).

\section{MINDFULNESS AS PARALLEL ACTIVATION AND COMBINATION OF SENSORS AND REACTORS}

The analysis of flying basics, of Tornado crew interaction and of the repertoires of flying practices allows to draw some considerations.

First and more generally, in Tornado crews sensor-reactor systems of different level of specialization coexist, as it is typical of complex systems. This evidence is in line with the literature, predicting that in complex environments, organization systems do not evolve into highly specialized systems devoted to univocally address peculiar environments, rather both general and specialized systems are present (Winter, 2004).

Second and more specifically, our analytical framework allowed to map sensors and reactors individually, and to trace their combination. Combinations occurred in order to respond to novel and 
TABLE 3. Vertical AND HORIZONTAL DIMENSIONS OF THE SENSOR-REACTOR SYSTEM AND THEIR INTERPLAY

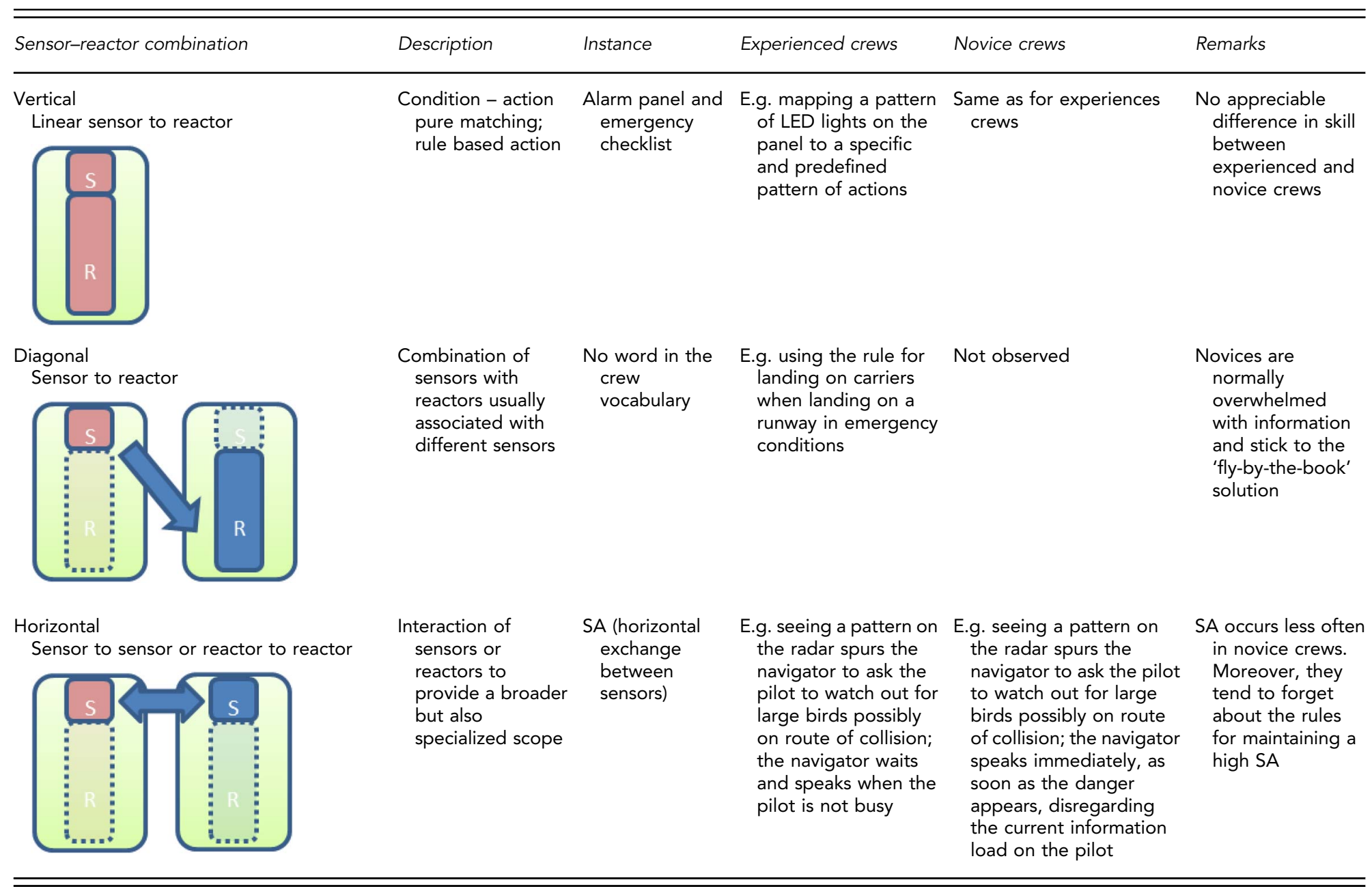


unexpected situations that are typical of the environment where our micro high reliability organizations is operating.

We could identify three main combination patterns in our empirical observations (see Table 3). First, we observed the vertical combination of sensors and reactors of the same degree of specialization. These include condition-action matching rules that in Tornados can be seen, for example, in the association between the Alarm panel of LED lights and the emergency checklist. This is the typical combination occurring in specialized routines and has been identified in the literature as the combination organizations naturally evolve towards (March, 1991; Levinthal \& March, 1993; Winter, 2004). The vertical combination is provided to all crew members by contingency procedures and is implemented with no appreciable difference by experienced and novice crew members.

Second, we observed the diagonal combination of sensors and reactors that do not constitute a system, are not designed as such, and are not usually combined in normal situations. Diagonal combinations represent creative associations between a sensor that would usually activate a certain reactor, with a different one. Tornado crews do not have a word that describes this combination. They talk about it as a very smart solution to an extremely difficult problem. An instance of such category in Tornado crews is, for example, the adoption of landing rules typical of carriers while landing on a runway in emergency conditions. This is a combinatorial ability that we observed for expert crew members only, and the validity of this observation was confirmed by interviews. As a matter of fact, novices are usually overwhelmed with information coming from different sensors and the only response strategy they can implement is the 'fly-by-the-book' solution. This diagonal combination is consistent with the literature showing that routines as response systems build a repertoire of behaviours the organization or the individual can draw upon to respond to uncertain and new situations (Bigley \& Roberts, 2001; Weick \& Sutcliffe, 2001).

Third, we observed horizontal combinations where the same kind of components (either sensors or reactors) are connected. In the realm of sensors, on Tornados, the horizontal dimension can be mapped as the concurrent activation of sensors constituting SA. Similarly, the concurrent use of basic rules with avionic and emergency check lists is an example from the realm of reactors. The horizontal combination of sensors or reactors is clear to both expert and novice crews as it is formalized. However, novices tend to focus their attention on single components and forget to support the continuous interaction of sensors or reactors of different kind.

This latter interaction artificially hampers the convergence towards specialized systems only. The horizontal combination implies the parallel activation of components. This is achieved though the definition of routines that impose the concurrent use of general and specialized sensors or general and specialized reactors. The horizontal combination also allows to buy time for the adaptation. This time is necessary for the refinement of sensors and reactors which act with a nearer focus or more specifically. In an after-the-fact perspective, the definition of times and opportunities to discuss experience (Rerup, 2009) and near-misses in particular (March, Sproull \& Tamuz, 1991; Weick \& Roberts, 1993) can belong to the same category, as an exercise where people try to adopt different perspectives and frameworks to understand the potential threats of the situation.

Our empirical analysis provides an inductive definition of mindfulness as the parallel activation and combination of sensors and reactors that allows the efficient and rapid deployment of responses but also the continuous reassessment of the situation. Such parallel activation and combination of sensors and reactors offers the concurrent pursuit of reliability and efficiency in Tornado crews. It is achieved both through spontaneous practices and through the deliberate design of crew interaction patterns. These patterns builds a micro-organization displaying both the advantages of specialization stemming from a rigid division of labour and the resilience afforded by the redundancy in the information gathering. 


\section{ACKNOWLEDGEMENTS}

We would like to thank General Claudio Zappulla, chief of the "Comando forze Aerotattiche" of the Italian National Airforce (ret.), Brigadier General Silvano Frigerio, Commander of the 6th FightingBombing Wing during data collection and the whole personnel of the 6th Fighting-Bombing Wing for their collaboration with the conduction of the field study on which this paper is based. The authors wish to acknowledge the financial contribution of the MIUR PRIN 05 project nr. 2005132154 "Designing, producing and using complex artefacts for managing and organizing firm knowledge".

\section{References}

Ashforth, B. E., \& Fried, Y. (1988). The mindlessness of organizational behaviors. Human Relations, 41(4), 305-329.

Becker, M. C. (2004). Organizational routines: A review of the literature. Industrial and Corporate Change, 13(4), 643-678.

Bigley, G. A., \& Roberts, K. H. (2001). The incident command system: High-reliability organizing for complex and volatile task environments. Academy of Management Journal, 44(6), 1281-1299.

Cohen, W. M., \& Levinthal, D. A. (1990). Absorptive capacity: A new perspective on learning and innovation. Administrative Science Quarterly, 35, 128-152.

Denrell, J., \& March, J. G. (2001). Adaptation as information restriction: The hot stove effect. Organization Science, 12(5), 523-538.

Glaser, B. G. (1978). Theoretical sensitivity: Advances in the methodology of grounded theory. Mill Valley, CA: Sociology Press.

Glaser, B. G. (1992). Emergence vs forcing: Basics of grounded theory analysis. Mill Valley, CA: Sociology Press.

Glaser, B. G., \& Strauss, A. L. (1967). The discovery of grounded theory: Strategies in qualitative research. London: Wiedenfeld and Nicholson.

Heiner, R. A. (1983). The origin of predictable behavior. The American Economic Review, 73(4), 560-595.

Kantur, D., \& Iseri-Say, A. (2012). Organizational resilience: A conceptual integrative framework. Journal of Management \& Organization, 18(6), 762-773.

La Porte, T. R. (1996). High reliability organizations: Unlikely, demanding and at risk. Journal of Contingencies and Crisis Management, 4(2), 60-71.

Langer, E. J. (1989). Mindfulness. Reading, MA, USA: Addison-Wesley/Addison Wesley Longman.

LaPorte, T. R., \& Consolini, P. M. (1991). Working in practice but not in theory: Theoretical challenges of "high-reliability organizations". Journal of Public Administration Research and Theory: J-PART, 1(1), 19-48.

Le Coze, J. (2008). Disasters and organisations: From lessons learnt to theorising. Safety Science, 46(1), 132-149.

Lekka, C. (2011). High Reliability Organisations: A Review of the Literature. Health and Safety Executive Research Reports., edited by Health and Safety Laboratory. The National Archives ed. Vol. RR 899. London: Health and Safety Executive. Retrieved from http://www.hse.gov.uk/research/rrpdf/rr899.pdf

Levinthal, D., \& Rerup, C. (2006). Crossing an apparent chasm: Bridging mindful and less-mindful perspectives on organizational learning. Organization Science, 17(4), 502-513.

Levinthal, D. A., \& March, J. G. (1993). The myopia of learning. Strategic Management Journal, 14(S2), 95-112.

March, J. G. (1991). Exploration and exploitation in organizational learning. Organization Science, 2(1), 71-87.

March, J. G. (2006). Rationality, foolishness, and adaptive intelligence. Strategic Management Journal, 27(3), 201-214.

March, J. G., Sproull, L. S., \& Tamuz, M. (1991). Learning from samples of one or fewer. Organization Science, 2(1), $1-13$.

Nelson, R. R., \& Winter, S. G. (1982). An evolutionary theory of economic change. Cambridge, MA: Belknap Press of Harvard University Press.

Pentland, B. T., \& Rueter, H. H. (1994). Organizational routines as grammars of action. Administrative Science Quarterly, 39(3), 484-510.

Perrow, C. (1999). Normal accidents: Living with high risk technologies. Princeton, NJ: Princeton University Press.

Rerup, C. (2005). Learning from past experience: Footnotes on mindfulness and habitual entrepreneurship. Scandinavian Journal of Management, 21(4), 451-472. 
Rerup, C. (2009). Attentional triangulation: Learning from unexpected rare crises. Organization Science, 20(5), 876-893.

Rerup, C., \& Levinthal, D. A. (2014). Situating the concept of organizational mindfulness: The multiple dimensions of organizational learning. In G. Becke (Ed.), Mindful change in times of permanent reorganization (pp. 33-48). Berlin Heidelberg: Springer.

Roberts, K. H. (1990). Some characteristics of one type of high reliability organization. Organization Science, 1(2), $160-176$.

Siggelkow, N. (2007). Persuasion with case studies. Academy of Management Journal, 50(1), 20-24.

Suddaby, R. (2006). From the editors: What grounded theory is not. Academy of Management Journal, 49(4), 633-642.

Sutcliffe, K. M., \& Vogus, T. J. (2014). Organizing for mindfulness. In A. Ie, C. T. Ngnoumen, \& E. J. Langer (Eds.), The Wiley Blackwell handbook of mindfulness (pp. 407-423). Chichester, UK: Wiley Blackwell.

Vaughan, D. (2004). Theorizing disaster: Analogy, historical ethnography, and the challenger accident. Ethnography, 5(3), 315-347.

Weick, K., \& Sutcliffe, K. M. (2001). Managing the unexpected: Assuring high performance in an age of complexity. San Francisco, CA: Jossey Bass Publishers.

Weick, K. E., \& Roberts, K. H. (1993). Collective mind in organizations: Heedful interrelating on flight decks. Administrative Science Quarterly, 38(3), 357-381.

Weick, K. E., \& Sutcliffe, K. M. (2006). Mindfulness and the quality of organizational attention. Organization Science, $17(4), 514-524$.

Weick, K., Sutcliffe, K., \& Obstfeld, D. (1999). Organizing for high reliability: Processes of collective mindfulness. Research in Organizational Behavior, 21, 23-81.

Winter, S. G. (2004). Specialised perception, selection, and strategic surprise: Learning from the moths and bees. Long Range Planning, 37(2), 163-169.

Yin, R. K. (1994). Case study research: Design and methods. Thousand Oaks, CA: Sage. 